\title{
Subclinical auditory dysfunction: Relationship between distortion product otoacoustic emissions and the audiogram.
}

Naomi F. Bramhall ${ }^{1,2}$, Garnett P. McMillan ${ }^{1,3}$, Amy N. Mashburn ${ }^{1,4}$

${ }^{1}$ VA RR\&D National Center for Rehabilitative Auditory Research (NCRAR), VA Portland Health Care System, Portland, OR

${ }^{2}$ Department of Otolaryngology/Head \& Neck Surgery, Oregon Health \& Science University, Portland, OR

${ }^{3}$ Department of Public Health and Preventive Medicine, Oregon Health \& Science University, Portland, OR

${ }^{4}$ Department of Audiology and Speech Pathology, University of Tennessee Health Science Center, Knoxville, TN

Corresponding Author:

Naomi Bramhall

Naomi.bramhall@,va.gov

3710 SW US Veterans Hospital Road (P5 NCRAR)

Portland, OR 97239

$503-220-8262 \times 54692$

Conflict of Interest Statement: There are no relevant conflicts of interest

Funding Statement: This work was supported by VA RR\&D award \#C1484-M (to NFB), \#C2104-W (to NFB), and \#C9230-C (to NCRAR) and the Veterans Health Administration Office of Academic Affiliations. 


\begin{abstract}
Purpose: Both distortion product otoacoustic emissions (DPOAEs) and pure tone thresholds have been used to account for the impacts of subclinical outer hair cell (OHC) dysfunction on auditory perception and measures of auditory physiology. However, the relationship between DPOAEs and the audiogram is unclear. This study investigated this relationship by determining how well DPOAE levels can predict the pure tone audiogram among individuals with clinically normal hearing. Additionally, the impacts of age, noise exposure history, and the perception of tinnitus on the ability of DPOAE levels to predict the audiogram were evaluated.
\end{abstract}

Method: Suprathreshold DPOAE levels from 1-10 kHz and pure tone thresholds from 0.25-16 kHz were measured in 366 ears from 194 young adults (19-35 years) with clinically normal audiograms (thresholds $\leq 20 \mathrm{~dB}$ HL from $0.25-8 \mathrm{kHz}$ ) and normal middle ear function. The measured DPOAE levels at all frequencies were used to predict each pure tone frequency. Participants were grouped based on age, self-reported noise exposure history/Veteran status, and self-report of tinnitus.

Results: Inclusion of DPOAE levels in the pure tone threshold prediction model improved threshold predictions at all frequencies from $0.25-16 \mathrm{kHz}$ compared with a model based only on sample mean pure tone thresholds, but these improvements were modest ( 0.4 to $2.1 \mathrm{~dB})$. DPOAE levels for $f_{2}$ frequencies of 4 and $5 \mathrm{kHz}$ were particularly influential in predicting pure tone thresholds above $4 \mathrm{kHz}$. However, the prediction accuracy of the model varied based on participant characteristics. On average, predicted pure tone thresholds were better than measured thresholds among Veterans, individuals with tinnitus, and the oldest age group (31-35 years). In contrast, predicted thresholds tended to be poorer than measured thresholds among the youngest age group (19-25 years) and non-Veterans. 
Conclusions: These results indicate a complex relationship between DPOAE levels and the pure tone audiogram. Underestimation of pure tone thresholds related to Veteran status, perception of tinnitus, and older age suggests that additional factors other than OHC damage may impact pure tone thresholds among individuals within these categories. These findings suggest that DPOAE levels and pure tone thresholds may differ in terms of how well they reflect subclinical OHC dysfunction.

\section{Introduction}

Among individuals with clinically normal audiograms, pure tone thresholds can vary considerably (from -10 to $20 \mathrm{~dB} \mathrm{HL}$ ). This variation is thought to be driven in large part by outer hair cell (OHC) damage (Wu et al., 2020). Otoacoustic emissions (OAEs) are often used as an indicator of $\mathrm{OHC}$ function, because they are reduced when OHCs are damaged or missing due to the reduction in cochlear gain (Brownell, 1990). Given the known relationships between OHC damage and both OAEs and the audiogram, one might expect that it would be relatively easy to predict the audiogram using distortion product otoacoustic emissions (DPOAEs). However, previous attempts at predicting pure tone thresholds in this manner have had limited success (e.g., Kimberley et al., 1994). These results suggest either that there are factors other than $\mathrm{OHC}$ function that impact the audiogram or that DPOAEs may not accurately represent OHC damage. Clarification of the relationship between DPOAEs and the audiogram is important because both measures are commonly used indicators of subclinical OHC dysfunction in studies that assess physiological measures of "hidden" auditory damage and the associated the perceptual impacts. 
In the past, many researchers were interested in using DPOAEs to predict pure tone thresholds so that hearing loss could be identified in difficult to test populations, such as children or patients who were unable to provide a behavioral response. These studies included ears with both normal and abnormal pure tone thresholds. The techniques used in these investigations varied. Some studies used DPOAE thresholds to predict the behavioral hearing threshold at the corresponding frequency (Boege \& Janssen, 2002; de Paula Campos \& Carvallo, 2011; Gorga et al., 2003; Rogers et al., 2010), while others used suprathreshold DPOAE levels to predict hearing thresholds (de Waal et al., 2002; Wagner \& Plinkert, 1999). One approach used the DPOAE level at $f_{2}$ as well as adjacent frequencies to predict the matching pure tone threshold (Harris et al., 1989). Kimberley et al. (1994) used a computer-based model to predict pure tone thresholds using DPOAE levels and age as inputs. They found weak correlations between DPOAE levels and behavioral hearing thresholds. However, they were able to predict whether an individual had clinically normal or impaired hearing based on their DPOAEs and age with approximately $85 \%$ accuracy. Overall, the ability of DPOAEs to predict pure tone thresholds in these studies was modest at best.

It is unclear why DPOAEs, which are accepted in the field as a relatively accurate measure of $\mathrm{OHC}$ function, would perform so poorly at predicting the audiogram. There are several possible explanations: 1) an incorrectly specified statistical model, 2) DPOAEs do not reflect $\mathrm{OHC}$ function as accurately as assumed, and 3) functional variation of aspects of the auditory system, other than OHCs, are impacting pure tone thresholds. Provided that the statistical model is reasonable and that DPOAEs are an accurate measure of $\mathrm{OHC}$ function, consistent discrepancies between observed and predicted pure tone thresholds suggest that 
damage to other parts of the auditory system (e.g., inner hair cells (IHCs), cochlear synapses, auditory nerve fibers, auditory brainstem, auditory cortex) are contributing to the audiogram.

The goal of this study was to determine how well a suprathreshold DPOAE primary sweep (DP-gram) from 1-10 kHz can predict the pure tone audiogram, including the extended high frequencies from 9-16 kHz, among individuals with clinically normal hearing and varying noise exposure histories. In contrast to historical studies that attempted to predict the audiogram using DPOAEs, this study modeled the effect of the entire DP-gram on the entire audiogram, including the extended high frequencies, in a single coherent analytical framework. The hypothesis was that 1) DPOAE prediction of pure tone thresholds would be poorer at low frequencies due to the lack of DPOAE data below $1 \mathrm{kHz}$ and measurement error introduced by biological noise, 2) DPOAEs at a particular $f_{2}$ frequency would contribute to the prediction of audiometric thresholds at and above that frequency because both the primary tones used to evoke DPOAEs and the backwards traveling wave must pass through the cochlear region basal to the region being stimulated, and 3) DPOAEs would underestimate audiometric thresholds among individuals at increased risk for cochlear synaptopathy, as indicated by Veteran status, older age, and/or the perception of tinnitus.

\section{Methods}

\section{Participants}

Military Veterans and non-Veterans, aged 19 to 35 years, were recruited from previous studies conducted at the National Center for Rehabilitative Auditory Research (NCRAR), by posting flyers at the Portland VA and Portland area colleges and universities, and by contacting 
individuals in a database of young Veterans who have previously received care through the Portland VA. A total of 194 participants from two different studies conducted at the NCRAR were included in the analysis. Results from these studies have been described previously (Bramhall et al., 2018; Bramhall et al., 2017; Bramhall et al., 2019; Bramhall et al., 2020), although some of the participants included in this analysis did not meet the DPOAE criteria to be included in previous reports. Inclusion criteria included: normal air conduction thresholds $(\leq 20$ $\mathrm{dB}$ HL from 0.25 to $8 \mathrm{kHz}$ ) with no evidence of a noise notch, no more than one $15 \mathrm{~dB}$ air-bone gap with no air-bone gaps greater than $15 \mathrm{~dB}$, and a normal tympanogram $(226 \mathrm{~Hz}$ tympanogram, compliance $0.3-1.9 \mathrm{ml}$, and peak pressure between $\pm 50 \mathrm{dPa}$ ). The participants were also required to have no history of concussion or significant otologic symptoms. Some participants met these criteria only in a single ear, resulting in a total of 366 ears for the analysis.

\section{Procedures}

All study procedures were approved by the Institutional Review Board of the Veterans Administration (VA) Portland Health Care System.

Audiometric Testing: Pure tone thresholds for the standard audiometric frequencies ( 0.25 to 8 $\mathrm{kHz}$ ) were assessed in all participants in $5 \mathrm{~dB}$ steps. In addition, audiometric thresholds from 9 to $16 \mathrm{kHz}$ were measured using Sennheiser HDA 200 headphones (Old Lyme, CT) in all but 19 participants (32 ears). No pure tone thresholds were beyond the limits of the audiometer at any frequency.

Otoacoustic Emissions Testing: DPOAE testing was conducted using a custom system that includes an ER-10 B+ probe microphone and EMAV software from Boys Town National Research Hospital (Neely \& Liu, 1993). DPOAEs were obtained in all participants using a DP- 
gram from $f_{2}=1$ to $10 \mathrm{kHz}$ in $1 / 6$-octave increments at stimulus frequency levels of $L_{1}=65$ and $L_{2}=55 \mathrm{~dB}$ SPL. If the DPOAE level was less than $-20 \mathrm{~dB}$ SPL or the signal-to-noise ratio was less than $6 \mathrm{~dB}$, the DPOAE level was set at $-20 \mathrm{~dB}$ SPL.

Assessment of Noise Exposure and Tinnitus: All non-Veteran participants either completed a questionnaire that asked about their lifetime occupational and recreational noise exposure, including firearm use (the Lifetime Exposure to Noise and Solvents Questionnaire (LENS-Q, Bramhall et al., 2017; Gordon et al., 2017) or were screened with questions about previous occupational or recreational noise exposure and asked if they had ever used a firearm. Most Veteran participants also completed the LENS-Q, including a section on military noise exposure. Veterans reported a variety of noise exposure histories, but almost all reported firearm use at some point during their military service. Non-Veterans all reported minimal occupational and recreational noise exposure and were divided into two groups based on any self-reported use of firearms: Non-Veteran Controls and Non-Veteran Firearms. To assess tinnitus, all study participants answered the following question on a questionnaire: "Do you have constant or frequent ringing in the ears?". Those reporting ringing in the test ear were marked as having tinnitus.

\section{Statistical Analysis}

A Bayesian approach was used to fit a function-on-function regression model (see Scheipl et al., 2015) of each ear's audiogram on its DP-gram. The pure tone threshold measured on the $i^{\text {th }}$ ear at audiometric frequency $f_{P T T}$ is denoted by $y_{i}^{f_{\text {PTT }}}$, where $f_{P T T}=\{0.25,0.5,1,2$, $3,4,6,8,9,10,11.2,12.5,14,16 \mathrm{kHz}\}$. These pure tone thresholds at individual frequencies can be combined to make up an audiogram, defined as $\boldsymbol{y}_{\boldsymbol{i}}$, which is a vector with 14 elements 
corresponding to the pure tone thresholds at each frequency. Bold-faced symbols indicate vectors or matrices. The audiograms are assumed to be multivariate normal random variables such that

$$
\boldsymbol{y}_{\boldsymbol{i}} \sim N\left(\boldsymbol{\mu}_{\boldsymbol{i}}, \Sigma\right)
$$

where $\sum$ is a first-order auto-regressive covariance matrix with heterogeneous diagonal elements. Defining $\sum$ in this manner allows the residual variability to differ according to audiometric frequency. The parameter $\boldsymbol{\mu}_{\boldsymbol{i}}$ represents the predicted audiogram for the $i^{t h}$ ear.

The effects of the DP-gram on $\boldsymbol{\mu}_{\boldsymbol{i}}$ are modeled as a functional predictor. The $i^{\text {th }}$ ear's DP-gram, denoted by $\boldsymbol{x}_{\boldsymbol{i}}$, is a vector of 11 elements composed of DPOAE levels measured at 11 $f_{2}$ primary frequencies $f_{D P O A E}$, where $f_{D P O A E}=\{1,1.2,1.5,2,2.5,3,4,5,6,8,10 \mathrm{kHz}\}$. Conceptually, the goal is to predict the $i^{\text {th }}$ ear's audiogram $\boldsymbol{y}_{\boldsymbol{i}}$ with the same ear's DP-gram $\boldsymbol{x}_{\boldsymbol{i}}$. This is accomplished by identifying a frequency-specific weight function that transforms the DPgram into a predicted pure tone threshold for each audiometric frequency. This concept is illustrated in Figure 1. The DP-gram (left) is multiplied by the weight function for each audiometric frequency (middle) to predict the pure tone threshold at that audiometric frequency (right). The weight functions are basically audiometric frequency-specific regression coefficients. This is similar to a standard regression analysis. In this case the regression coefficients correspond to the weights and the predictors correspond to the DPOAE levels. The name "function-on-function" regression implicates a functional response (the audiogram) and a functional predictor (the DP-gram). The statistical problem is that of estimating the weight functions given the available data.

The simplest way to predict the audiogram is to use a model where $\boldsymbol{\mu}_{\boldsymbol{i}}$ is equal to the mean pure tone threshold at each audiometric frequency, or rather, more precisely, a vector of independent model intercepts at each frequency. Because the predicted audiogram is simply the 
sample mean audiogram, the weight function for this model is equal to zero across all $f_{D P O A E}$ and $f_{P T T}$ and the predicted audiogram will be identical for all ears regardless of their DPOAE levels. This simple model was fit to the data to serve as a baseline for comparison with a more elaborate model that includes DPOAEs and is referred to as the "mean audio model".

Another, intuitively appealing model to consider has independent regression coefficients for each DPOAE level on each $f_{P T T}$. This results in a model with 154 independent regression coefficients $\left(11 f_{D P O A E}\right.$ effects $\left.\times 14 f_{P T T}=154\right)$. Although this model should predict the sample data quite well, it will generalize poorly to other samples because it will tend to overfit the data due to high correlations between DPOAE levels across $f_{D P O A E}$. The result of this type of model is a set of weight functions, one per audiometric frequency, that appears jagged across $f_{D P O A E}$ with a high degree of uncertainty.

An alternative approach is to treat both the audiogram and the DP-gram as continuous functions sampled at discrete frequencies. This is sensible because the audiometric test frequencies and the $\mathrm{DPOAE} f_{2}$ primaries were chosen by convention. It is possible to obtain data from additional test frequencies if time and equipment allows. With the $i^{\text {th }}$ ear's DP-gram now written as a function of $f_{D P O A E}$, i.e. $x_{i}\left(f_{D P O A E}\right)$, the predicted pure tone threshold $\mu_{i}^{f P T T}$ at audiometric frequency $f_{P T T}$ can be represented as

$$
\mu_{i}^{f_{P T T}}=\int x_{i}\left(f_{D P O A E}\right) \cdot \beta\left(f_{P T T}, f_{D P O A E}\right) d f_{D P O A E}
$$

This equation indicates that integration occurs over the $f_{2}$ frequencies of the DP-gram, weighted according to the regression coefficient function $\beta$. These integrals comprise the mean vector $\boldsymbol{\mu}_{\boldsymbol{i}}$ in equation (1). Low-rank smoothing begins by representing each frequency in the audiogram or DP-gram as a collection of nine basis functions, rather than as 14 or 11 discrete frequencies, respectively. Specifically, the discrete approximation for each audiometric frequency is 
calculated from the product of the DP-gram (measured at discrete steps) multiplied by a tensor product basis constructed from marginal 5-knot cubic B-splines in the $\log _{2}\left(f_{P T T}\right)$ and the $\log _{2}\left(f_{D P O A E}\right)$ dimensions and its coefficient $\boldsymbol{\beta}$. This approach reduces the number of unknown coefficients to 81 compared to the 154 for the independent coefficients model described in the previous paragraph and by imposing a "roughness" penalty on the coefficient surface, it induces smoothing across frequency for the regression coefficients. The notation for this model is quite complex, so please refer to Scheipl et al. (2015, section 1.1) and Wood et al. (2012) for more detail. This model is referred to as the "full model".

A random intercept is often included as a modeling parameter to account for subject-tosubject variation that is otherwise not accounted for in the model. In this analysis, a random intercept could be used to account for subject-to-subject variation in the audiogram that is not accounted for by DPOAEs. This approach is often motivated by the notion that left- and right-ear audiograms within subjects are correlated. A random intercept was not included in the current analysis because one of the goals of this analysis was to qualitatively investigate subject-level features such as age, noise exposure, or perception of tinnitus that might affect the ability to predict the audiogram from the DP-gram. Therefore, it would be counterproductive to adjust for subject-level variation.

The mean audio model and the full model were fit in SAS software v9.4M5 with PROC BGLIMM assuming flat priors on all of the model parameters. Three chains were run using the No-U-Turn sampler for the variance components and conjugate sampling for the remaining effects with random starting values in each chain. Convergence was achieved after 10,000 posterior samples. 


\section{Results}

\section{Sample and group characteristics}

An overview of the characteristics of the sample, including the breakdown by age and noise exposure group, number of males/females, and number of individuals reporting tinnitus are shown in Table 1. This table shows that there are 114 Veterans, 65 non-Veteran controls, and 15 non-Veterans with firearm use in this sample. Fifty-four participants reported tinnitus, most of them Veterans. The participants are fairly evenly split into three groups based on age $(19-25,26-$ 30, and 31-35 years) and these groups are relatively balanced in terms of sex. Audiograms and DP-grams for the age, noise exposure, and tinnitus groups are plotted in Figure $\mathbf{2}$ and Figure 3, respectively. Average pure tone thresholds decrease with age, Veteran status, and report of tinnitus. Audiometric differences are particularly noticeable at $12.5 \mathrm{kHz}$ and higher. Surprisingly, average audiometric thresholds at $14-16 \mathrm{kHz}$ are better for the Non-Veteran Firearms group than for the Non-Veteran Control or Veteran groups. DP-grams show lower average DPOAE levels from 2-10 kHz for the two older age groups (26-30 and 31-35 years) compared to the youngest age group (19-25 years), although the DPOAEs for the two older groups are similar. On average, Veterans have lower DPOAE levels across $f_{D P O A E}$ compared to the other noise exposure groups, while the non-Veterans with firearm use have the largest DPOAE levels, except at $f_{D P O A E}=10 \mathrm{kHz}$. The perception of tinnitus is associated with lower average DPOAE levels beginning at $f_{D P O A E}=3 \mathrm{kHz}$.

\section{Correlations between DPOAE levels and pure tone thresholds}

Pearson correlation coefficients between the pure tone thresholds at each $f_{P T T}$ and the DPOAE levels at each $f_{D P O A E}$ are shown in Table 2. Scatterplots illustrating these relationships 
can be found in the Supplemental Data. The poorest correlation between DPOAE levels and pure tone thresholds was at $f_{D P O A E}=f_{P T T}=1 \mathrm{kHz}$, where the correlation coefficient was -0.15 . The strongest correlations were observed between the DPOAE levels at $f_{D P O A E}=4$ and $5 \mathrm{kHz}$ and the pure tone threshold at $f_{P T T}=4 \mathrm{kHz}(-0.42$ to -0.45$)$ and the DPOAE levels at $f_{D P O A E}=5,6$, and $8 \mathrm{kHz}$ and the pure tone threshold at $f_{P T T}=6 \mathrm{kHz}(-0.44$ to -0.49$)$. Interestingly, the DPOAE levels at $f_{D P O A E}=4$ and $5 \mathrm{kHz}$ had correlations with pure tone thresholds in the extended high frequencies $\left(f_{P T T}=9-16 \mathrm{kHz}\right)$ that were as strong or stronger $(-0.21$ to -.031$)$ than the correlations between the DPOAE levels at $f_{D P O A E}=8$ and $10 \mathrm{kHz}$ and the extended high frequency $\left(f_{P T T}=9-16 \mathrm{kHz}\right)$ pure tone thresholds $(-0.10$ to -0.25$)$.

\section{Impact of DPOAE levels on pure tone threshold predictions}

Root mean square prediction errors (RMSPEs) for the full model are shown for each pure tone threshold frequency in Table 3. RMSPEs increase as $f_{P T T}$ increases, ranging from $5 \mathrm{~dB}$ at $0.25 \mathrm{kHz}$ to $18.9 \mathrm{~dB}$ at $16 \mathrm{kHz}$. Prediction accuracy is poorest in the extended high frequencies $\left(f_{P T T}=9-16 \mathrm{kHz}\right)$. RMSPEs for the mean audio model are also shown in Table 3, along with the difference in RMSPEs between the two models. Prediction accuracy is better (by 0.4 to $2.1 \mathrm{~dB}$ )

for the full model, even for $f_{P T T}$ where DPOAEs were not measured $(0.25,0.5,9,11.2,12.5,14$, and $16 \mathrm{kHz})$.

The regression coefficient (or weight) applied to each DPOAE level when predicting the pure tone audiogram is plotted in Figure 4. Overall, the DPOAE level at the $f_{D P O A E}$ corresponding to the $f_{P T T}$ does not have a greater weight than other $f_{D P O A E}$. In fact, for pure tone thresholds at $f_{P T T} \leq 3 \mathrm{kHz}$, the DPOAE level at $f_{D P O A E}=2 \mathrm{kHz}$ has the largest weight and for 
pure tone thresholds at $f_{P T T} \geq 6 \mathrm{kHz}$, the DPOAE levels at $f_{D P O A E}=4$ and $5 \mathrm{kHz}$ have the largest weights.

Figure 5 illustrates the impact on the predicted audiogram of decreasing the DPOAE levels at $f_{D P O A E}=3,4$, and $5 \mathrm{kHz}$. It is clear from this plot that a dramatic notch in the DPOAE levels has limited impact on predicted pure tone thresholds at the corresponding $f_{P T T}$. Interestingly, decreasing the DPOAE level at $f_{D P O A E}=3,4$, and $5 \mathrm{kHz}$ results in poorer predicted pure tone thresholds not only at $f_{P T T}=3,4$, and $5 \mathrm{kHz}$, but also a similar change in all pure tone thresholds where $f_{P T T} \geq 2 \mathrm{kHz}$.

Examples of predicted and observed audiograms are shown for nine ears in Figure 6. These examples were chosen to demonstrate the range of prediction error patterns observed in the sample. In the ideal case, the predicted audiogram closely approximates the measured audiogram (Figure 6E). However, in some ears, predicted thresholds are smaller (better) than observed thresholds (Figure 6F), or are larger (poorer) than observed thresholds (Figure 6D). In other ears, the pattern is less straightforward, with predicted thresholds that are better than observed for low $f_{P T T}$ and poorer than observed for high $f_{P T T}$ (Figure 6B) or vice versa (Figure 6H).

Audiograms are poorer than predicted among the oldest group, but better than predicted in the youngest group

Average residuals at each $f_{P T T}$ (the predicted threshold minus the observed threshold) for each age group are plotted in Figure 7. On average, predicted audiograms for the oldest age group (31-35 years) are better than the actual measured audiograms, particularly for $f_{P T T} \geq 6$ $\mathrm{kHz}$ ( 0.7 to $8.6 \mathrm{~dB}$ better). In contrast, the opposite pattern is observed for the youngest age 
group (19-25 years), where predicted audiograms are poorer than measured audiograms for $f_{P T T}$ $\geq 2 \mathrm{kHz}$ ( -0.3 to $-4.3 \mathrm{~dB}$ poorer). Average prediction errors are minimal for the middle group (26-30 years). Mean residuals for each age group are shown by frequency in Table 4.

Audiograms are poorer than predicted among Veterans, but better than predicted in nonVeterans

Average residuals are plotted by $f_{P T T}$ according to noise exposure group in Figure 8. Predicted audiograms for Veterans show better thresholds than the measured audiograms on average. This is true across $f_{P T T}$, with positive residuals (ranging from 0.1 to $3.9 \mathrm{~dB}$ ) at all $f_{P T T}$ except 10 and $11.2 \mathrm{kHz}$, where the residuals are -0.1 and $-0.7 \mathrm{~dB}$ respectively. The reverse is observed for non-Veterans, where the predicted audiograms are poorer than the actual audiograms. Among non-Veterans reporting any history of firearm use, predicted audiograms are worse than measured audiograms for $f_{P T T} \geq 12.5 \mathrm{kHz}$ (residuals range from -2.0 to $-7.3 \mathrm{~dB}$ ). Among non-Veteran controls, residuals are negative at all $f_{P T T}$ except 0.5 and $16 \mathrm{kHz}$, ranging from $-0.1 \mathrm{~dB}$ to $-1.7 \mathrm{~dB}$. Mean residuals for each noise exposure group are shown by $f_{P T T}$ in Table 4.

Audiograms are poorer than predicted among individuals with tinnitus, but not individuals without tinnitus

Average residuals for each $f_{P T T}$ are plotted by tinnitus group in Figure 9. On average, predicted audiograms for individuals with tinnitus are better than observed at all $f_{P T T}$, except 10 and $11.2 \mathrm{kHz}$ (residuals of -0.9 and $-0.4 \mathrm{~dB}$ ), with residuals ranging from 0.7 to $6.3 \mathrm{~dB}$. Mean residuals are close to zero across $f_{P T T}$ for individuals without tinnitus. Mean residuals for each tinnitus group are shown by $f_{P T T}$ in Table 4 . 


\section{Discussion}

\section{Ability of DPOAE levels to predict individual pure tone thresholds}

Across $f_{P T T}$, prediction errors for the full statistical model that included DPOAE levels were smaller than for than the model based only on average pure tone thresholds. However, the magnitude of this improvement was quite small. Adding DPOAEs to the statistical model only improved prediction errors by 0.4 to $2.1 \mathrm{~dB}$.

Prediction accuracy in the standard audiometric range $\left(f_{P T T}=0.25-8 \mathrm{kHz}\right)$ was close to the test-retest reliability of clinical audiometric thresholds $( \pm 5 \mathrm{~dB})$. In the extended high frequencies $\left(f_{P T T}=9-16 \mathrm{kHz}\right)$, prediction accuracy was considerably poorer $(9-19 \mathrm{~dB})$.

DPOAE levels at $f_{D P O A E}=4$ and $5 \mathrm{kHz}$ had greater weights than DPOAEs at other frequencies in terms of predicting pure tone thresholds for $f_{P T T} \geq 6 \mathrm{kHz}$. This may be a consequence of the primary tones at $f_{1}$ and $f_{2}$ and the backwards traveling wave passing through more basal regions of the cochlea and therefore increasing sensitivity to basal cochlear damage. Additionally, given the relatively young age of all participants in this study, we would expect most $\mathrm{OHC}$ damage in the sample to be related to noise exposure and therefore expect a high correlation with the DPOAE levels in the $4 \mathrm{kHz}$ region.

DPOAE levels at $f_{D P O A E}=4$ and $5 \mathrm{kHz}$ were weighted higher in terms of predicting the pure tone thresholds for $f_{P T T}=9-16 \mathrm{kHz}$ than the DPOAE levels at $f_{D P O A E}=8$ and $10 \mathrm{kHz}$. One explanation for this finding is that noise exposure-related $\mathrm{OHC}$ damage in the $4 \mathrm{kHz}$ cochlear region is highly correlated with $\mathrm{OHC}$ damage at the extreme base of the cochlea. This is consistent with animal studies that have demonstrated two damage foci in response to noise 
exposure, one at the tonotopic region with maximal noise-induced vibration (equivalent to the 4 $\mathrm{kHz}$ region in humans) and one in the basal hook region (Fried et al., 1976; Wang et al., 2002).

Three possible explanations for why predicted audiograms might not correspond with measured audiograms were described earlier: 1) inadequacy of the statistical model, 2) DPOAEs are not a sufficiently accurate measure of $\mathrm{OHC}$ function, and 3) pure tone thresholds vary as a function of auditory dysfunction other than OHC damage. In the following paragraphs, each of these explanations will be discussed in the context of the present analysis.

\section{Sufficiency of the statistical model}

In this analysis, a function-on-function regression model of the effects of the entire DPgram on the entire audiogram was developed. Though rooted in concepts that are at least 30 years old (Hastie \& Tibshirani, 1990), this type of analysis involves a relatively new methodology that is undergoing refinement at both the theoretical and computational levels. Though no model is inherently correct, we believe that this model offers the most flexible and coherent approach to addressing the complex functional data that is routinely collected in auditory research.

\section{Relationship between DPOAE levels and OHC function}

Harding et al. (2002) and Harding and Bohne (2004) present some of the most comprehensive animal data on the relationship between DPOAE levels and OHC function. They investigated the relationship between DPOAE level shifts and histopathology in noise exposed chinchillas. They observed that permanent DPOAE level shifts were associated with moderate to substantial OHC loss. However, they also found that small focal lesions with $100 \%$ loss of OHCs did not result in DPOAE level shifts at the corresponding frequency, potentially indicating that DPOAEs can be generated or supplemented by the activity of OHCs in other cochlear regions, 
particularly those basal to the damaged region. They also found that DPOAE levels are sensitive not only to OHC loss, but also the condition of the supporting cells. They concluded that DPOAE levels are useful for detecting broad OHC losses of greater than $10 \%$ and large focal OHC lesions greater than $0.6 \mathrm{~mm}$. Although these findings illustrate that DPOAEs generally reflect $\mathrm{OHC}$ integrity, they also show that there are limitations in terms of the accuracy with which DPOAEs can represent OHC damage.

\section{Audiograms may be impacted by factors other than $\mathrm{OHC}$ loss}

DPOAE levels underpredicted audiometric thresholds (i.e. predicted them to be better than measured) in Veterans, individuals with tinnitus, and the oldest age group (31-35 years). Both noise exposure and older age are associated with cochlear synapse loss in animal models (Kujawa \& Liberman, 2009; Sergeyenko et al., 2013). Age-related cochlear synaptopathy has been confirmed in humans through temporal bone studies (Viana et al., 2015; Wu et al., 2019) and military noise exposure has been associated with reduced auditory brainstem response (ABR) wave I amplitude (Bramhall et al., 2017), a physiological indicator of synaptopathy in animal models (Kujawa \& Liberman, 2009). Tinnitus is one predicted perceptual consequence of synaptopathy (Kujawa \& Liberman, 2015). Several human studies have shown relationships between physiological indicators of synaptopathy and the perception of tinnitus (Bramhall et al., 2018; Bramhall et al., 2019; Gu et al., 2012; Paul et al., 2017; Schaette \& McAlpine, 2011; Wojtczak et al., 2017). As a measure of peripheral auditory function, specifically $\mathrm{OHC}$ function, DPOAEs should not be impacted by synaptopathy. In contrast, because audiometric thresholds require a behavioral response, they can theoretically be impacted by damage at any point in the auditory system. Synaptopathy is generally assumed not to have an effect on auditory thresholds because animal models suggest that low spontaneous rate/high threshold auditory nerve fibers 
are the most vulnerable to synaptic loss (Furman et al., 2013; Schmiedt et al., 1996). Given that the detection of sound at threshold is coded by high spontaneous rate/low threshold fibers, the impact of synaptopathy on behavioral thresholds is expected to be minimal. In addition, a study of chinchillas with extensive carboplatin-induced IHC loss showed that up to $80 \%$ of IHCs could be lost before resulting in behavioral threshold shifts, suggesting that thresholds can be coded by a very small proportion of IHCs forming synapses with auditory nerve fibers (Lobarinas et al., 2013). Similarly, Chambers et al. (2016) found that in a mouse model with approximately $95 \%$ loss of spiral ganglion neurons, behavioral pure tone thresholds were relatively unchanged from controls. This suggests that only a small percentage of functional auditory nerve fibers are necessary for tone detection. However, it is perhaps an oversimplification to assume that synaptopathy has no effect on audiometric thresholds. If one looks more closely at the data from Lobaranis et al. (see their Figure 7), there is variability across animals in terms of auditory thresholds after damage, with some animals showing threshold shifts of up to $10 \mathrm{~dB}$ at any particular frequency, even with as little as 35\% IHC loss. Therefore, although large changes in audiometric thresholds are not an expected result of synaptopathy, threshold shifts of up to $10 \mathrm{~dB}$ would not be inconsistent with the animal data. The underpredictions shown here for Veterans, individuals with tinnitus, and the oldest age group are on the order of 1-8 $\mathrm{dB}$ and could therefore be explained by synaptopathy-related threshold shifts.

Alternatively, the underpredictions in these groups could be due to the lack of DPOAE data for $f_{D P O A E}>10 \mathrm{kHz}$ in this sample. Noise exposure, tinnitus, and older age may lead to greater $\mathrm{OHC}$ loss in the extended high frequencies. This could result in an underestimate of $\mathrm{OHC}$ damage in these groups when using DPOAE measurements only out to $f_{D P O A E}=10 \mathrm{kHz}$. However, this would only be expected to impact pure tone threshold predictions above $f_{P T T}=10$ 
$\mathrm{kHz}$ and does not explain why in the Tinnitus and Veteran groups, thresholds are underpredicted across the frequency range.

\section{Predicted audiograms are poorer than measured audiograms among the youngest age group and non-Veterans}

For the youngest age group (19-25 years) and non-Veterans, DPOAE levels predicted thresholds to be worse than what was observed, particularly for high $f_{P T T}$. One explanation for this finding is the presence of subclinical OHC dysfunction that was "hidden" from the pure tone thresholds. This is consistent with previous studies that have indicated that DPOAEs are more sensitive to noise- or ototoxin-induced OHC damage than pure tone thresholds (Engdahl \& Kemp, 1996; Littman et al., 1998; Marshall et al., 2009; Seixas et al., 2005; Stavroulaki et al., 2002). The older age groups and the Veterans would also be expected to have OHC damage, likely to an even greater degree. However, if the amount of synaptopathy is higher in these groups (or if they have more $\mathrm{OHC}$ damage in the cochlear regions above $10 \mathrm{kHz}$ that was not detected by the DPOAEs), this could counteract the overprediction of pure tone thresholds due to higher sensitivity of DPOAEs to OHC dysfunction, resulting in a net underprediction of thresholds.

\section{Limitations}

This study only included DPOAE measurements out to $f_{D P O A E}=10 \mathrm{kHz}$. Ideally, DPOAE levels would have been obtained out to $16 \mathrm{kHz}$ so that the ability of DPOAEs level to predict audiometric thresholds in the extended high frequencies could be better assessed. The higher RMSPEs for pure tone threshold predictions in the extended high frequencies $\left(f_{P T T}=9\right.$ - 
$16 \mathrm{kHz})$ compared to the standard audiometric frequencies $\left(f_{P T T}=0.25-8 \mathrm{kHz}\right)$ may be due in part to the limited DPOAE data available for these $f_{D P O A E}$.

In this sample there is overlap between the groups that is not uniform. For example, more participants in the Veteran group fall into the two older age groups than the youngest age group. The non-Veterans disproportionately fall into the youngest age group. Also, Veterans are more likely to have tinnitus than the non-Veterans. This means that the observed age, Veteran, and tinnitus effects are not necessarily independent from each other. This is not unexpected as older age, Veteran status, and tinnitus are all associated with increased noise exposure and are difficult to separate.

The Non-Veteran Firearms group in this study is quite small, with only 15 subjects (compared to 114 Veterans and 65 Non-Veteran Controls), so it's difficult to form conclusions about this particular noise exposure group based on the limited amount of data.

This study only investigated the relationship between suprathreshold DPOAE levels (where $L_{1} / L_{2}=65 / 55 \mathrm{~dB}$ SPL) and the audiogram. DPOAE thresholds or DPOAE levels measured in response to other primary tone levels may yield different results.

\section{Conclusions}

Overall, these findings indicate a somewhat complicated relationship between DPOAE levels and the audiogram, where pure tone thresholds may be better predicted by off frequency DPOAE levels and impacted by factors other than $\mathrm{OHC}$ function. These results should be considered when choosing test measures for subclinical OHC damage. 


\section{Acknowledgements}

The research described here was supported by the the Department of Veterans Affairs, Veterans Health Administration, Rehabilitation Research and Development Service - Awards \#C1484-M (to NFB), \#C2104-W (to NFB), and \#C9230-C (to NCRAR) and the Veterans Health Administration Office of Academic Affiliations (to ANM). Research audiologist support was also provided by the Department of Defense Hearing Center of Excellence and zCore Business Solutions, Inc.. The opinions and assertions presented are private views of the authors and are not to be construed as official or as necessarily reflecting the views of the VA or the Department of Defense. 


\section{References}

Boege, P., \& Janssen, T. (2002). Pure-tone threshold estimation from extrapolated distortion product otoacoustic emission $\mathrm{I} / \mathrm{O}$-functions in normal and cochlear hearing loss ears. $J$ Acoust Soc Am, 111(4), 1810-1818.

Bramhall, N. F., Konrad-Martin, D., \& McMillan, G. P. (2018). Tinnitus and Auditory Perception After a History of Noise Exposure: Relationship to Auditory Brainstem Response Measures. Ear Hear, 39(5), 881-894.

Bramhall, N. F., Konrad-Martin, D., McMillan, G. P., \& Griest, S. E. (2017). Auditory Brainstem Response Altered in Humans With Noise Exposure Despite Normal Outer Hair Cell Function. Ear Hear, 38(1), e1-e12.

Bramhall, N. F., McMillan, G. P., Gallun, F. J., \& Konrad-Martin, D. (2019). Auditory brainstem response demonstrates that reduced peripheral auditory input is associated with selfreport of tinnitus. J Acoust Soc Am, 146(5), 3849.

Bramhall, N. F., Niemczak, C. E., Kampel, S. D., Billings, C. J., \& McMillan, G. P. (2020). Evoked Potentials Reveal Noise Exposure-Related Central Auditory Changes Despite Normal Audiograms. Am J Audiol, 1-13.

Brownell, W. E. (1990). Outer hair cell electromotility and otoacoustic emissions. Ear Hear, $11(2), 82-92$.

Chambers, A. R., Resnik, J., Yuan, Y., Whitton, J. P., Edge, A. S., Liberman, M. C., \& Polley, D. B. (2016). Central Gain Restores Auditory Processing following Near-Complete Cochlear Denervation. Neuron, 89(4), 867-879.

de Paula Campos, U., \& Carvallo, R. (2011). Correlation between DPOAE I/O functions and pure-tone thresholds. Braz J Otorhinolaryngol, 77(6), 754-760.

de Waal, R., Hugo, R., Soer, M., \& Kruger, J. J. (2002). Predicting hearing loss from otoacoustic emissions using an artificial neural network. S Afr J Commun Disord, 49, 28-39.

Engdahl, B., \& Kemp, D. T. (1996). The effect of noise exposure on the details of distortion product otoacoustic emissions in humans. The Journal of the Acoustical Society of America, 99(3), 1573-1587.

Fried, M. P., Dudek, S. E., \& Bohne, B. A. (1976). Basal turn cochlear lesions following exposure to low-frequency noise. Trans Sect Otolaryngol Am Acad Ophthalmol Otolaryngol, 82(3 Pt 1), 285-298.

Furman, A. C., Kujawa, S. G., \& Liberman, M. C. (2013). Noise-induced cochlear neuropathy is selective for fibers with low spontaneous rates. J Neurophysiol, 110(3), 577-586. 
Gordon, J. S., Griest, S. E., Thielman, E. J., Carlson, K. F., Helt, W. J., Lewis, M. S., . . Henry, J. A. (2017). Audiologic characteristics in a sample of recently-separated military Veterans: The Noise Outcomes in Servicemembers Epidemiology Study (NOISE Study). Hear Res, 349, 21-30.

Gorga, M. P., Neely, S. T., Dorn, P. A., \& Hoover, B. M. (2003). Further efforts to predict puretone thresholds from distortion product otoacoustic emission input/output functions. $J$ Acoust Soc Am, 113(6), 3275-3284.

Gu, J. W., Herrmann, B. S., Levine, R. A., \& Melcher, J. R. (2012). Brainstem auditory evoked potentials suggest a role for the ventral cochlear nucleus in tinnitus. $J$ Assoc Res Otolaryngol, 13(6), 819-833.

Harding, G. W., \& Bohne, B. A. (2004). Temporary DPOAE level shifts, ABR threshold shifts and histopathological damage following below-critical-level noise exposures. Hear Res, 196(1-2), 94-108.

Harding, G. W., Bohne, B. A., \& Ahmad, M. (2002). DPOAE level shifts and ABR threshold shifts compared to detailed analysis of histopathological damage from noise. Hear Res, 174(1-2), 158-171.

Harris, F. P., Lonsbury-Martin, B. L., Stagner, B. B., Coats, A. C., \& Martin, G. K. (1989). Acoustic distortion products in humans: systematic changes in amplitudes as a function of f2/f1 ratio. $J$ Acoust Soc Am, 85(1), 220-229.

Hastie, T., \& Tibshirani, R. (1990). Generalized Additive Models. New York: Chapman and Hall.

Kimberley, B. P., Hernadi, I., Lee, A. M., \& Brown, D. K. (1994). Predicting pure tone thresholds in normal and hearing-impaired ears with distortion product emission and age. Ear Hear, 15(3), 199-209.

Kujawa, S. G., \& Liberman, M. C. (2009). Adding insult to injury: cochlear nerve degeneration after "temporary" noise-induced hearing loss. J Neurosci, 29(45), 14077-14085.

Kujawa, S. G., \& Liberman, M. C. (2015). Synaptopathy in the noise-exposed and aging cochlea: Primary neural degeneration in acquired sensorineural hearing loss. Hear Res, 330(Pt B), 191-199.

Littman, T. A., Magruder, A., \& Strother, D. R. (1998). Monitoring and predicting ototoxic damage using distortion-product otoacoustic emissions: pediatric case study. $J$ Am Acad Audiol, 9(4), 257-262.

Lobarinas, E., Salvi, R., \& Ding, D. (2013). Insensitivity of the audiogram to carboplatin induced inner hair cell loss in chinchillas. Hear Res, 302, 113-120. 
Marshall, L., Lapsley Miller, J. A., Heller, L. M., Wolgemuth, K. S., Hughes, L. M., Smith, S. D., \& Kopke, R. D. (2009). Detecting incipient inner-ear damage from impulse noise with otoacoustic emissions. J Acoust Soc Am, 125(2), 995-1013.

Neely, S., \& Liu, Z. (1993). EMAV: Otoacoustic emission averager. In Tech Memo No. 17: Boys Town National Research Hospital Omaha.

Paul, B. T., Bruce, I. C., \& Roberts, L. E. (2017). Evidence that hidden hearing loss underlies amplitude modulation encoding deficits in individuals with and without tinnitus. Hearing research, 344, 170-182.

Rogers, A., Burke, S., Kopun, J., Hongyang, T., Neely, S., \& Gorga, M. (2010). Influence of Calibration Method on DPOAE Measurements: II. Threshold Prediction. Ear and Hearing, 31(4), 546-554.

Schaette, R., \& McAlpine, D. (2011). Tinnitus with a normal audiogram: physiological evidence for hidden hearing loss and computational model. J Neurosci, 31(38), 13452-13457.

Scheipl, F., Staicu, A.-M., \& Greven, S. (2015). Functional Additive Mixed Models. J Comput Graph Stat, 24(2), 477-501.

Schmiedt, R. A., Mills, J. H., \& Boettcher, F. A. (1996). Age-related loss of activity of auditorynerve fibers. J Neurophysiol, 76(4), 2799-2803.

Seixas, N., Goldman, B., Sheppard, L., Neitzel, R., Norton, S., \& Kujawa, S. (2005). Prospective noise induced changes to hearing among construction industry apprentices. Occupational and environmental medicine, 62(5), 309-317.

Sergeyenko, Y., Lall, K., Liberman, M. C., \& Kujawa, S. G. (2013). Age-related cochlear synaptopathy: an early-onset contributor to auditory functional decline. $J$ Neurosci, 33(34), 13686-13694.

Stavroulaki, P., Vossinakis, I. C., Dinopoulou, D., Doudounakis, S., Adamopoulos, G., \& Apostolopoulos, N. (2002). Otoacoustic emissions for monitoring aminoglycosideinduced ototoxicity in children with cystic fibrosis. Arch Otolaryngol Head Neck Surg, $128(2), 150-155$.

Viana, L. M., O'Malley, J. T., Burgess, B. J., Jones, D. D., Oliveira, C. A., Santos, F., . . Liberman, M. C. (2015). Cochlear neuropathy in human presbycusis: Confocal analysis of hidden hearing loss in post-mortem tissue. Hear Res, 327, 78-88.

Wagner, W., \& Plinkert, P. K. (1999). The relationship between auditory threshold and evoked otoacoustic emissions. Eur Arch Otorhinolaryngol, 256(4), 177-188. 
Wang, Y., Hirose, K., \& Liberman, M. C. (2002). Dynamics of noise-induced cellular injury and repair in the mouse cochlea. Journal of the Association for Research in Otolaryngology, $3(3), 248-268$.

Wojtczak, M., Beim, J. A., \& Oxenham, A. J. (2017). Weak Middle-Ear-Muscle Reflex in Humans with Noise-Induced Tinnitus and Normal Hearing May Reflect Cochlear Synaptopathy. eNeuro, 4(6).

Wood, S., Scheipl, F., \& Faraway, J. (2012). Straightforward intermediate rank tensor product smoothing in mixed models. Statistics and Computing, 23(3), 341-360.

Wu, P. Z., Liberman, L. D., Bennett, K., de Gruttola, V., O'Malley, J. T., \& Liberman, M. C. (2019). Primary Neural Degeneration in the Human Cochlea: Evidence for Hidden Hearing Loss in the Aging Ear. Neuroscience, 407, 8-20.

Wu, P. Z., Wen, W. P., O'Malley, J. T., \& Liberman, M. C. (2020). Assessing fractional hair cell survival in archival human temporal bones. Laryngoscope, 130(2), 487-495. 


\begin{tabular}{|c|c|c|}
\hline $\begin{array}{l}\text { DP-gram } \\
\text { (dB SPL) }\end{array}$ & $X$ & $\begin{array}{l}\text { Weight Function } \\
\text { (dB HL / dB SPL) }\end{array}$ \\
\hline
\end{tabular}

DPOAE Level (dB SPL)
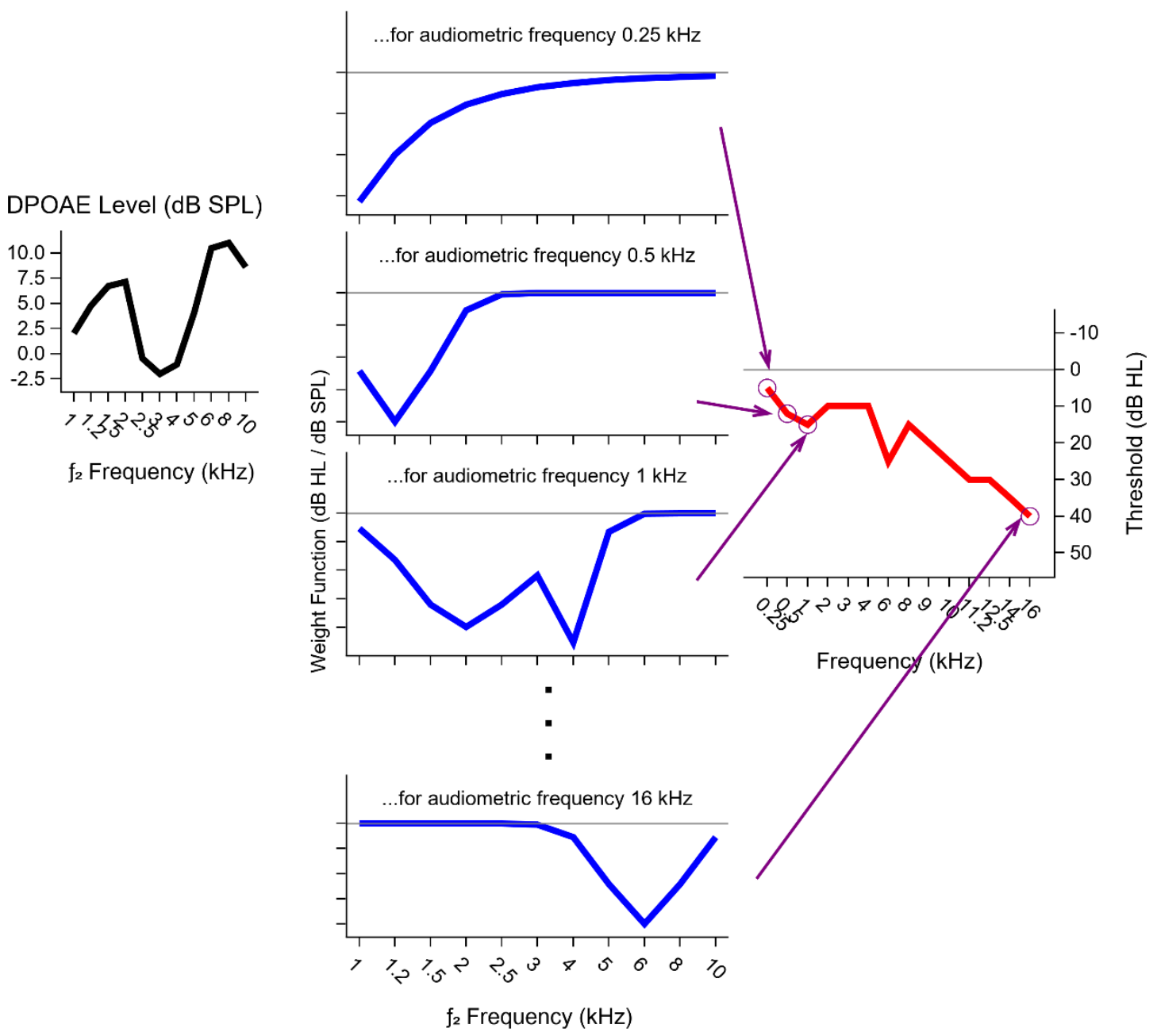

Figure 1. Schematic illustrating how pure tone threshold predictions are generated from DP-grams. The DP-gram (black line in the left panel) is multiplied by the weight function for each audiometric frequency $\left(f_{P T T}\right.$, blue lines in the middle panel) to predict the pure tone threshold at that $f_{P T T}$ (follow arrows to circles on the red line in the right panel). 

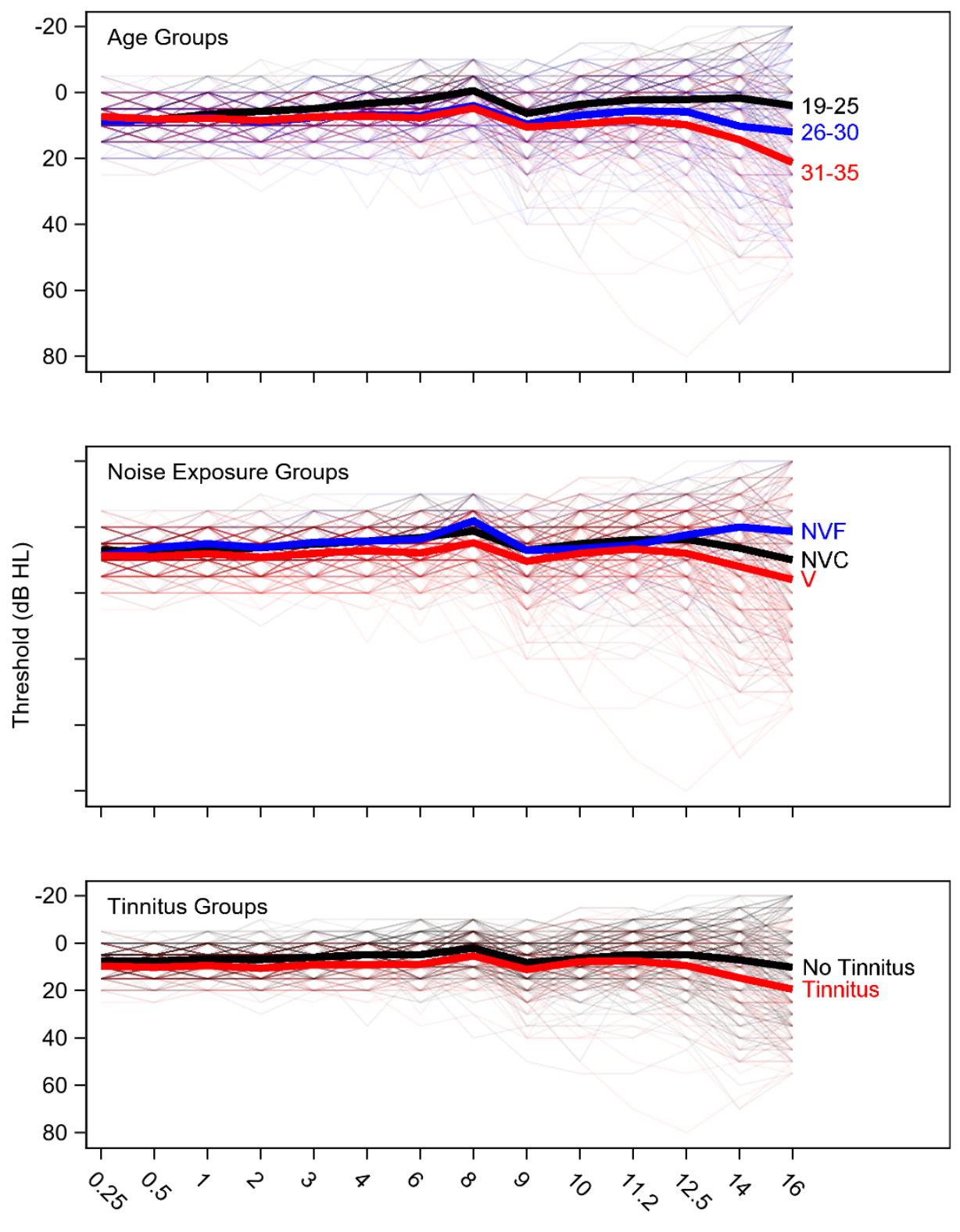

Frequency $(\mathrm{kHz})$

Figure 2. Audiometric thresholds by group. Audiograms are plotted by age group, noise exposure group, or tinnitus group. Groups are color-coded and mean data is shown with a thick line. Thin lines indicate data for individual ears. Note that the same ears are plotted in each subplot, but grouped differently. NVF $=$ Non-Veteran Firearms, NVC $=$ Non-Veteran Controls, $\mathrm{V}=$ Veterans 

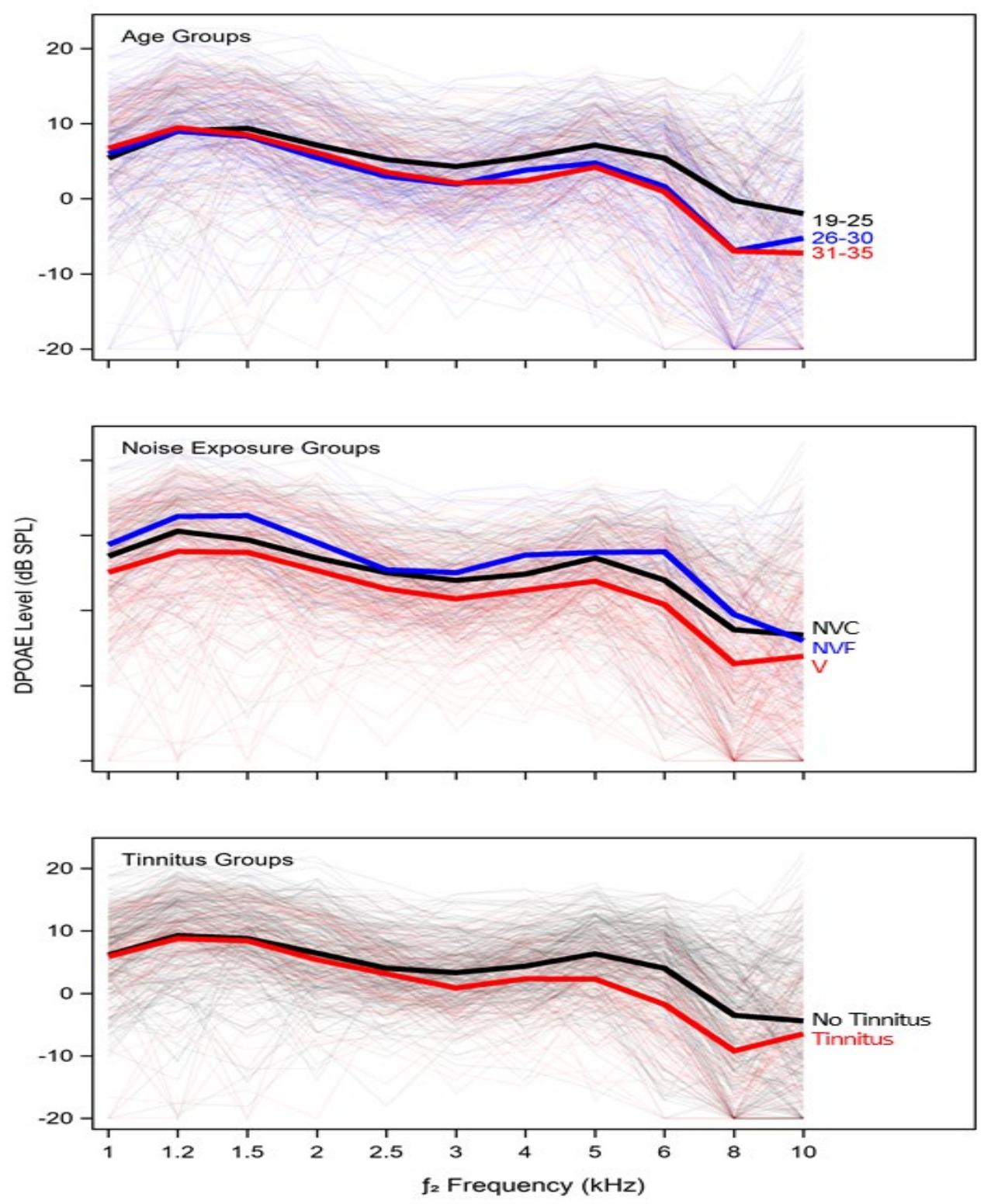

Figure 3. DPOAE levels by group. DP-grams are plotted by age group, noise exposure group, and tinnitus group. Mean data is shown with a thick line. Thin lines indicate data for individual ears. Note that the same ears are plotted in each subplot, but grouped differently. If the measured DPOAE level was less than $-20 \mathrm{~dB}$ SPL or the signal-to-noise ratio was less than $6 \mathrm{~dB}$, the DPOAE level was set at $-20 \mathrm{~dB}$ SPL. NVF $=$ Non-Veteran Firearms, NVC $=$ Non-Veteran Controls, $\mathrm{V}=$ Veterans 


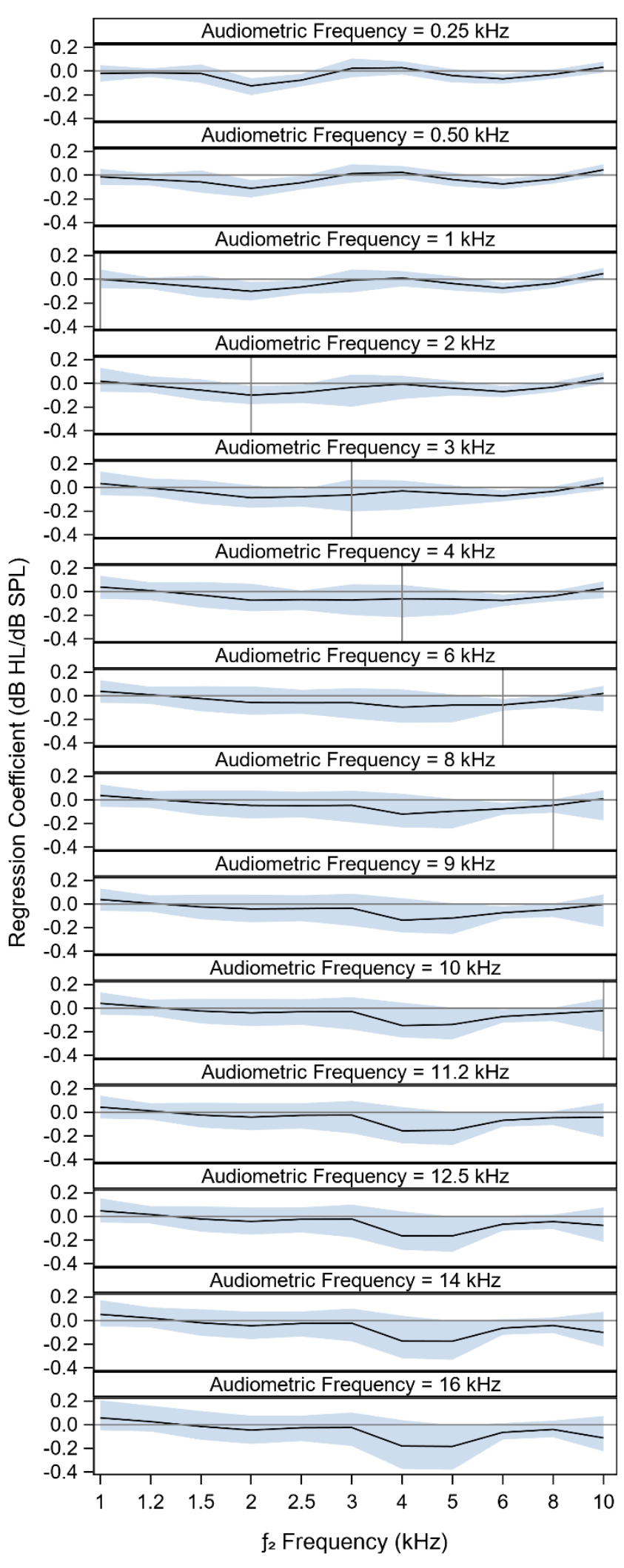

Figure 4. DPOAE weight functions.

DPOAE levels for the $f_{2}$ frequency

$\left(f_{D P O A E}\right)$ corresponding to the frequency

of the predicted audiometric threshold

$\left(f_{\text {PTT }}\right)$ do not have the biggest regression

coefficients (weights). Regression

coefficients are plotted for each

combination of $f_{P T T}$ and $f_{D P O A E}$. This

indicates the relative weight the DPOAE

level at the indicated $f_{D P O A E}$ contributes

to the predicted audiometric threshold at

$f_{P T T}$. The black line shows the median of

the posterior distribution and the blue

shaded region indicates the $90 \%$

confidence interval. Vertical black lines

show instances where $f_{D P O A E}$

corresponds to $f_{P T T}$. 


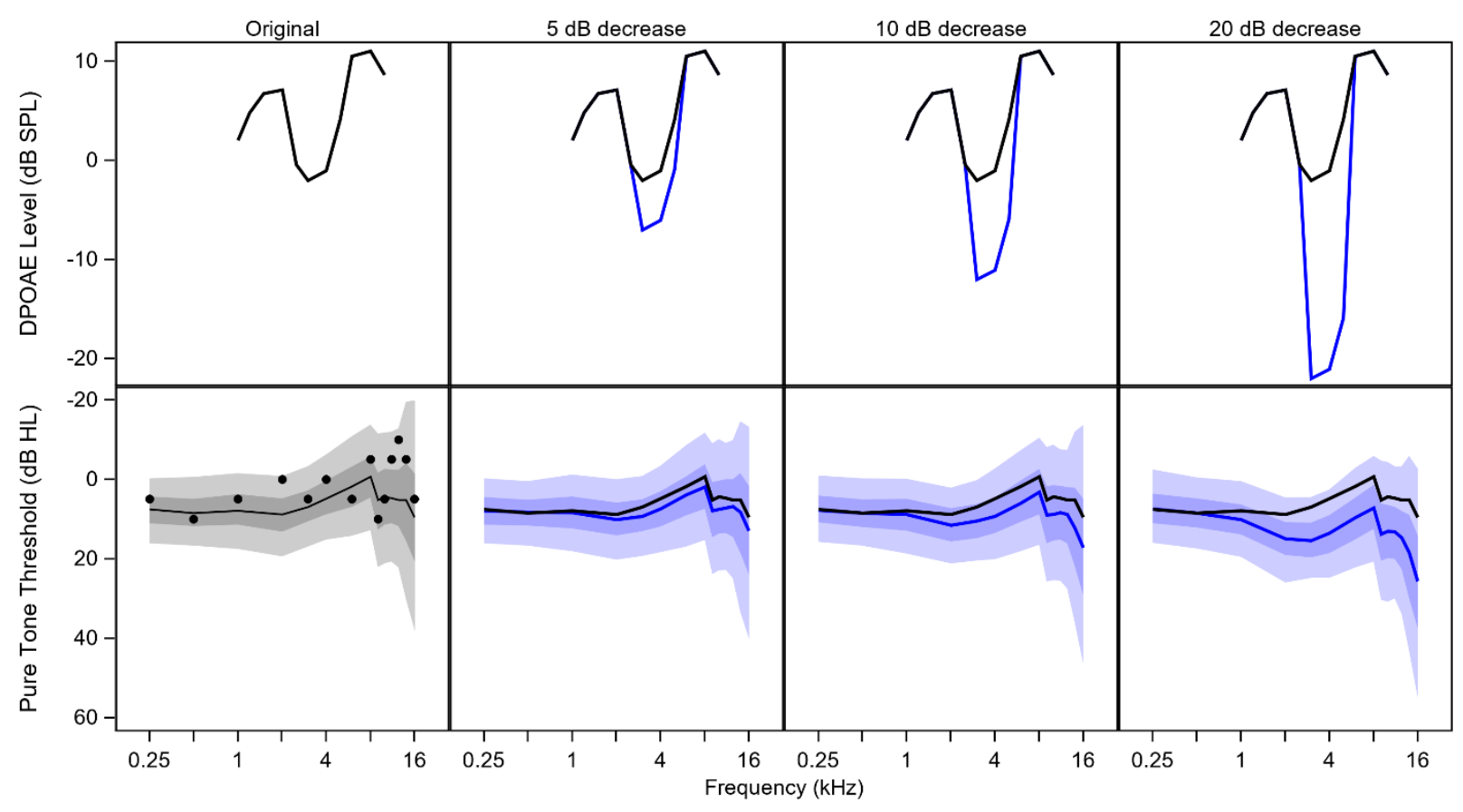

Figure 5. Impact of decreased DPOAE levels on pure tone thresholds. The shape of the audiogram is relatively insensitive to the shape of the DP-gram. DPOAE levels are plotted for an example ear in the top left, labeled "Original". Moving from left to right, the DPOAE levels at $f_{D P O A E}=3,4$, and $5 \mathrm{kHz}$ are decreased by 5,10 , or $20 \mathrm{~dB}$ (shown with the blue line). In the bottom row, black circles indicate measured pure tone thresholds. The black line shows the predicted thresholds before changing the DPOAE levels. The predicted pure tone thresholds after decreasing the DPOAE levels are shown with the blue line. Dark shaded regions show the $50^{\text {th }}$ percentile and light shaded regions show the $90^{\text {th }}$ percentile. 


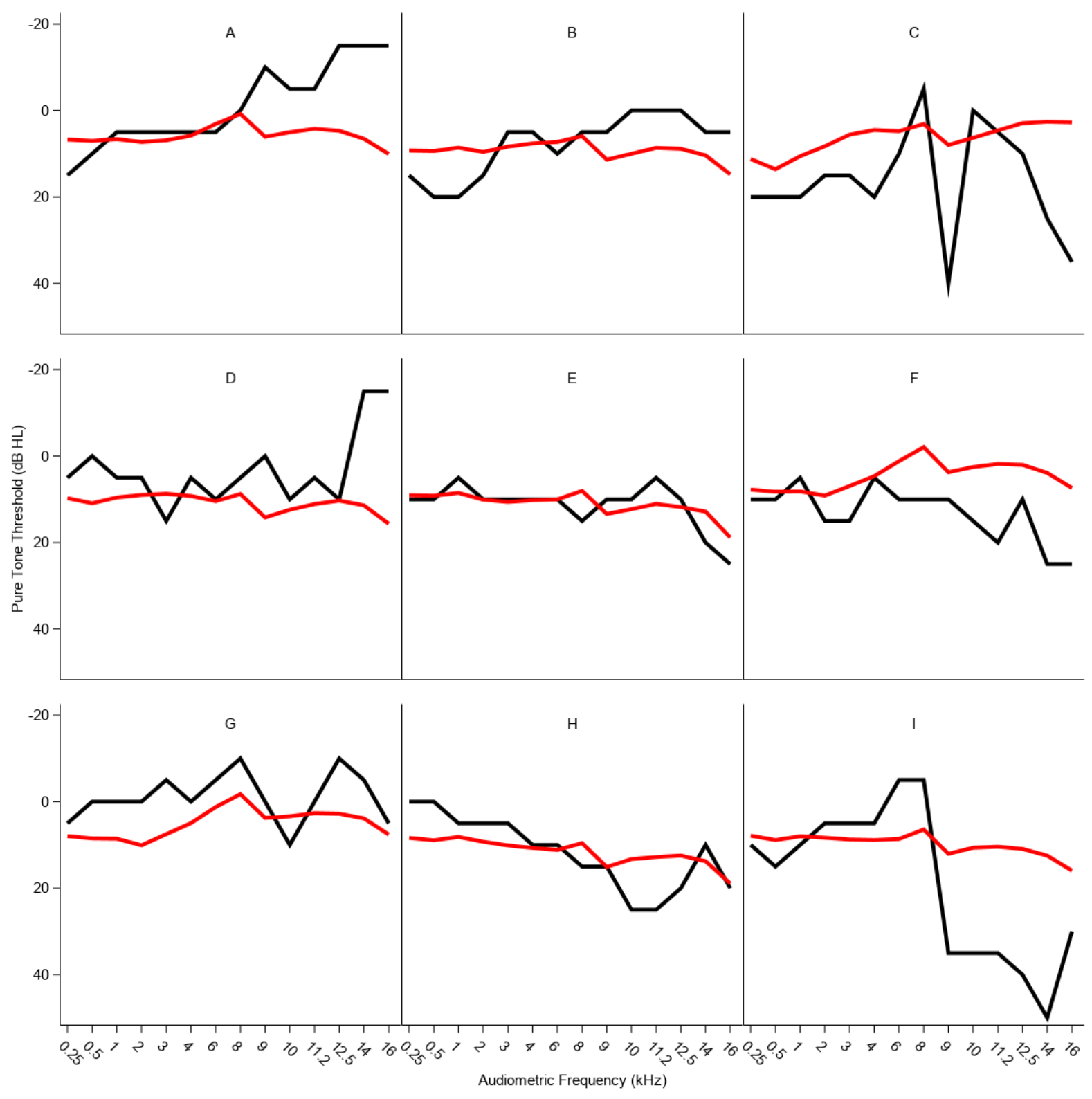

Figure 6. Examples of predicted versus observed audiograms. A variety of examples of predicted versus observed audiograms are plotted for individual ears to illustrate the various patterns that were observed. Observed audiograms are shown in black, predicted audiograms are shown in red. 


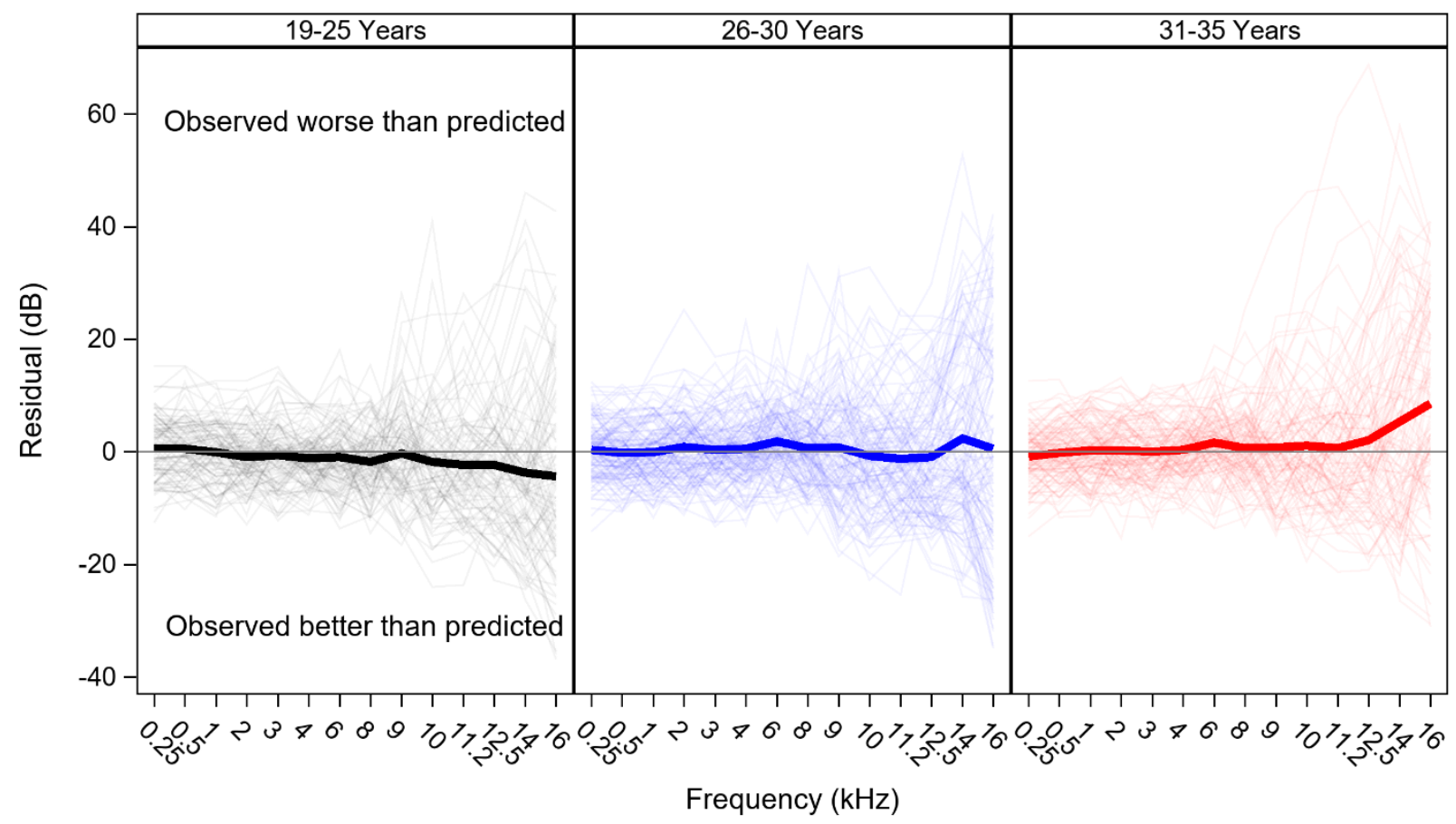

Figure 7. Residuals by age group. Pure tone thresholds are poorer (bigger) than predicted among the oldest age group, but better than predicted among the youngest age group. Residuals (observed thresholds minus predicted thresholds) are plotted for each $f_{P T T}$ by age group. Thick lines show mean residuals, thin lines show residuals for individual ears. 


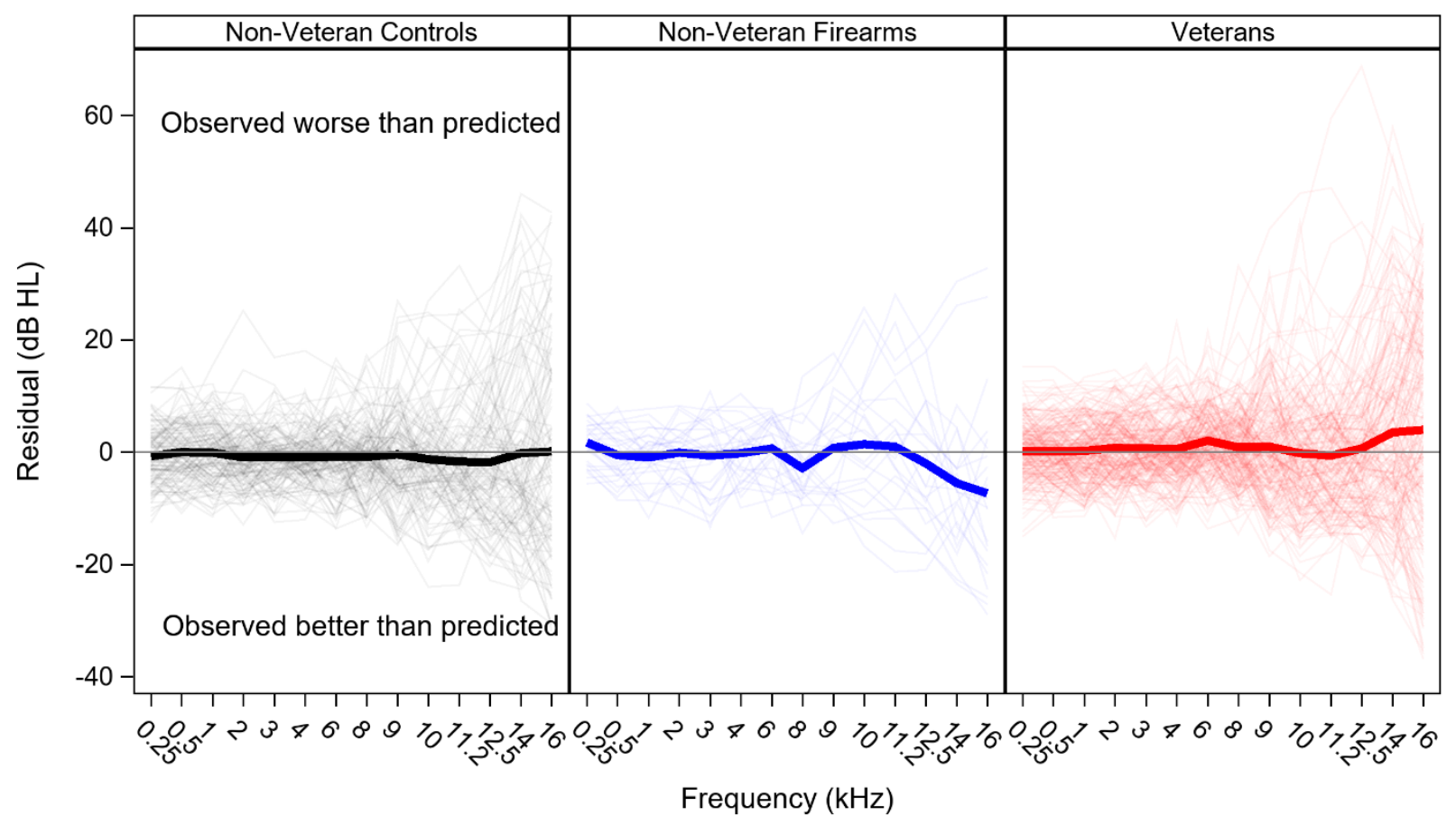

Figure 8. Residuals by noise exposure group. Pure tone thresholds are poorer than predicted among Veterans, but are better than predicted among non-Veterans. Residuals (observed thresholds minus predicted thresholds) are plotted for each $f_{P T T}$ by noise exposure group (NonVeteran Firearms, Non-Veteran Controls, and Veterans). Thick lines show mean residuals, thin lines show residuals for individual ears. 


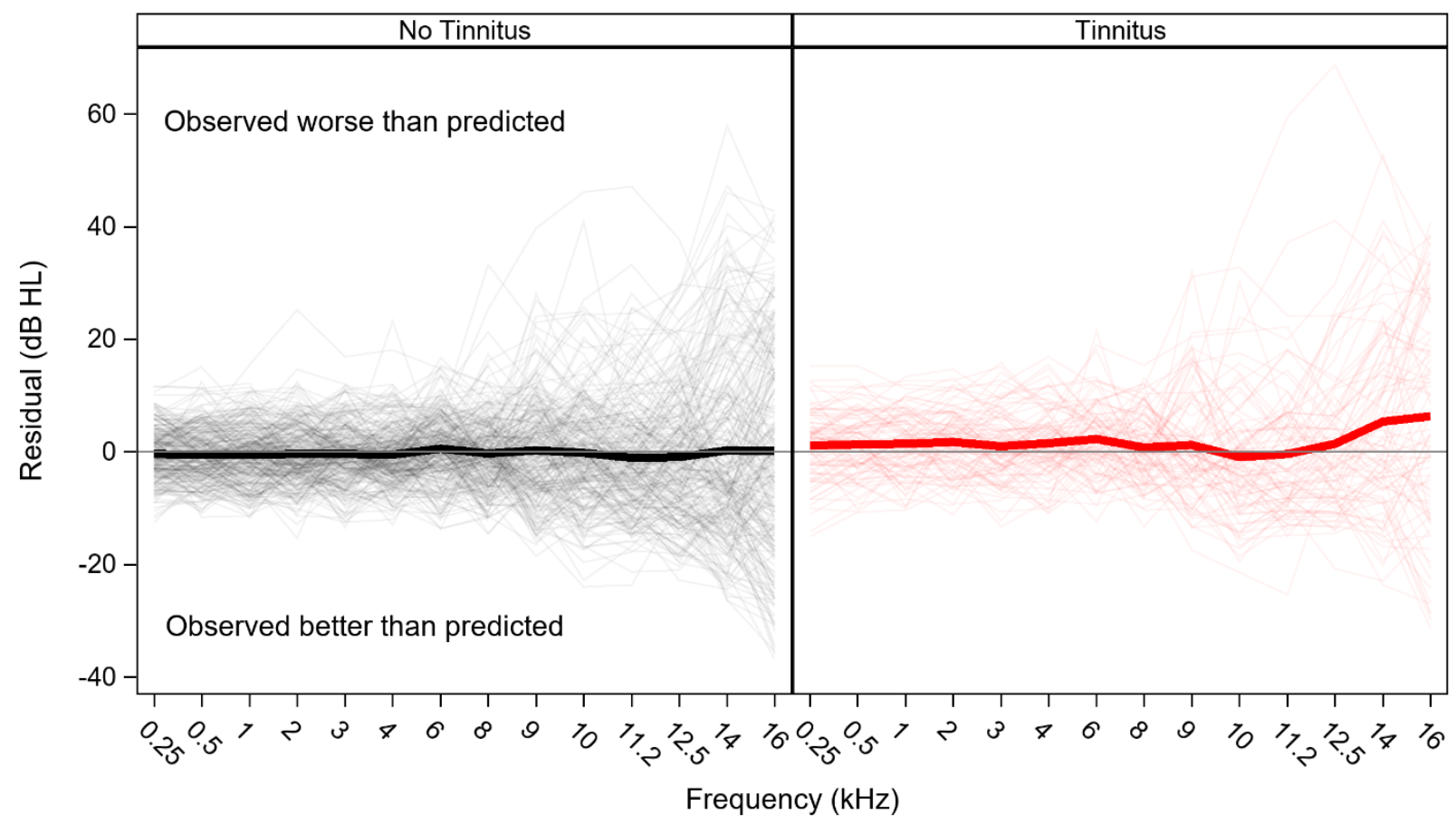

Figure 9. Residuals by tinnitus group. Pure tone thresholds are poorer than predicted among individuals reporting tinnitus, but not among individuals without tinnitus. Residuals (observed thresholds minus predicted thresholds) are plotted for each $f_{P T T}$ by noise exposure group. Thick lines show mean residuals, thin lines show residuals for individual ears. 
Table 1. Participant Characteristics

\begin{tabular}{|c|c|c|c|c|c|}
\hline & & & $\begin{array}{c}\text { Non-Veteran } \\
\text { Firearms }\end{array}$ & $\begin{array}{c}\text { Non-Veteran } \\
\text { Controls }\end{array}$ & Veterans \\
\hline Sex & Age (yrs) & Tinnitus & & & \\
\hline \multirow[t]{6}{*}{ Male } & $19-25$ & No & 3 & 12 & 4 \\
\hline & & Yes & 0 & 0 & 3 \\
\hline & $26-30$ & No & 1 & 4 & 15 \\
\hline & & Yes & 0 & 0 & 22 \\
\hline & $31-35$ & No & 2 & 5 & 16 \\
\hline & & Yes & 0 & 0 & 14 \\
\hline \multirow[t]{6}{*}{ Female } & $19-25$ & No & 4 & 20 & 6 \\
\hline & & Yes & 0 & 1 & 1 \\
\hline & $26-30$ & No & 4 & 13 & 9 \\
\hline & & Yes & 0 & 0 & 7 \\
\hline & $31-35$ & No & 1 & 8 & 13 \\
\hline & & Yes & 0 & 2 & 4 \\
\hline
\end{tabular}


Table 2. Correlations between DPOAE levels and pure tone thresholds

\begin{tabular}{|c|c|c|c|c|c|c|c|c|c|c|c|c|}
\hline \multicolumn{13}{|c|}{ DPOAE $f_{2}$ Frequency $(\mathrm{kHz})$} \\
\hline & & 1.0 & 1.2 & 1.5 & 2.0 & 2.5 & 3.0 & 4.0 & 5.0 & 6.0 & 8.0 & 10.0 \\
\hline \multirow{14}{*}{ 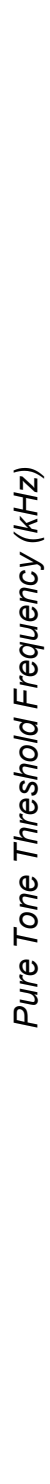 } & 0.25 & $\begin{array}{r}-0.15 \\
361\end{array}$ & $\begin{array}{r}-0.15 \\
363\end{array}$ & $\begin{array}{r}-0.23 \\
364\end{array}$ & $\begin{array}{r}-0.28 \\
365\end{array}$ & $\begin{array}{r}-0.23 \\
366\end{array}$ & $\begin{array}{r}-0.15 \\
366\end{array}$ & $\begin{array}{r}-0.18 \\
366\end{array}$ & $\begin{array}{r}-0.19 \\
366\end{array}$ & $\begin{array}{r}-0.12 \\
361\end{array}$ & $\begin{array}{r}-0.17 \\
332\end{array}$ & $\begin{array}{r}-0.03 \\
330\end{array}$ \\
\hline & 0.50 & $\begin{array}{r}-0.22 \\
361\end{array}$ & $\begin{array}{r}-0.24 \\
363\end{array}$ & $\begin{array}{r}-0.33 \\
364\end{array}$ & $\begin{array}{r}-0.30 \\
365\end{array}$ & $\begin{array}{r}-0.25 \\
366\end{array}$ & $\begin{array}{r}-0.21 \\
366\end{array}$ & $\begin{array}{r}-0.20 \\
366\end{array}$ & $\begin{array}{r}-0.20 \\
366\end{array}$ & $\begin{array}{r}-0.17 \\
361\end{array}$ & $\begin{array}{r}-0.21 \\
332\end{array}$ & $\begin{array}{r}0.01 \\
330\end{array}$ \\
\hline & 1.0 & $\begin{array}{r}-0.15 \\
361\end{array}$ & $\begin{array}{r}-0.13 \\
363\end{array}$ & $\begin{array}{r}-0.28 \\
364\end{array}$ & $\begin{array}{r}-0.28 \\
365\end{array}$ & $\begin{array}{r}-0.21 \\
366\end{array}$ & $\begin{array}{r}-0.25 \\
366\end{array}$ & $\begin{array}{r}-0.25 \\
366\end{array}$ & $\begin{array}{r}-0.22 \\
366\end{array}$ & $\begin{array}{r}-0.16 \\
361\end{array}$ & $\begin{array}{r}-0.19 \\
332\end{array}$ & $\begin{array}{r}0.00 \\
330\end{array}$ \\
\hline & 2.0 & $\begin{array}{r}-0.06 \\
361\end{array}$ & $\begin{array}{r}-0.05 \\
363\end{array}$ & $\begin{array}{r}-0.21 \\
364\end{array}$ & $\begin{array}{r}-0.33 \\
365\end{array}$ & $\begin{array}{r}-0.32 \\
366\end{array}$ & $\begin{array}{r}-0.36 \\
366\end{array}$ & $\begin{array}{r}-0.29 \\
366\end{array}$ & $\begin{array}{r}-0.27 \\
366\end{array}$ & $\begin{array}{r}-0.20 \\
361\end{array}$ & $\begin{array}{r}-0.22 \\
332\end{array}$ & $\begin{array}{r}-0.03 \\
330\end{array}$ \\
\hline & 3.0 & $\begin{array}{r}0.01 \\
361\end{array}$ & $\begin{array}{r}0.03 \\
363\end{array}$ & $\begin{array}{r}-0.07 \\
364\end{array}$ & $\begin{array}{r}-0.12 \\
365\end{array}$ & $\begin{array}{r}-0.17 \\
366\end{array}$ & $\begin{array}{r}-0.34 \\
366\end{array}$ & $\begin{array}{r}-0.36 \\
366\end{array}$ & $\begin{array}{r}-0.36 \\
366\end{array}$ & $\begin{array}{r}-0.22 \\
361\end{array}$ & $\begin{array}{r}-0.23 \\
332\end{array}$ & $\begin{array}{r}-0.08 \\
330\end{array}$ \\
\hline & 4.0 & $\begin{array}{r}0.04 \\
361\end{array}$ & $\begin{array}{r}0.05 \\
363\end{array}$ & $\begin{array}{r}-0.05 \\
364\end{array}$ & $\begin{array}{r}-0.11 \\
365\end{array}$ & $\begin{array}{r}-0.13 \\
366\end{array}$ & $\begin{array}{r}-0.27 \\
366\end{array}$ & $\begin{array}{r}-0.45 \\
366\end{array}$ & $\begin{array}{r}-0.42 \\
366\end{array}$ & $\begin{array}{r}-0.33 \\
361\end{array}$ & $\begin{array}{r}-0.31 \\
332\end{array}$ & $\begin{array}{r}-0.20 \\
330\end{array}$ \\
\hline & 6.0 & $\begin{array}{r}-0.11 \\
361\end{array}$ & $\begin{array}{r}-0.12 \\
363\end{array}$ & $\begin{array}{r}-0.22 \\
364\end{array}$ & $\begin{array}{r}-0.19 \\
365\end{array}$ & $\begin{array}{r}-0.20 \\
366\end{array}$ & $\begin{array}{r}-0.30 \\
366\end{array}$ & $\begin{array}{r}-0.37 \\
366\end{array}$ & $\begin{array}{r}-0.49 \\
366\end{array}$ & $\begin{array}{r}-0.44 \\
361\end{array}$ & $\begin{array}{r}-0.46 \\
332\end{array}$ & $\begin{array}{r}-0.35 \\
330\end{array}$ \\
\hline & 8.0 & $\begin{array}{r}-0.04 \\
361\end{array}$ & $\begin{array}{r}-0.08 \\
363\end{array}$ & $\begin{array}{r}-0.14 \\
364\end{array}$ & $\begin{array}{r}-0.16 \\
365\end{array}$ & $\begin{array}{r}-0.12 \\
366\end{array}$ & $\begin{array}{r}-0.22 \\
366\end{array}$ & $\begin{array}{r}-0.34 \\
366\end{array}$ & $\begin{array}{r}-0.34 \\
366\end{array}$ & $\begin{array}{r}-0.35 \\
361\end{array}$ & $\begin{array}{r}-0.33 \\
332\end{array}$ & $\begin{array}{r}-0.32 \\
330\end{array}$ \\
\hline & 9.0 & $\begin{array}{r}0.01 \\
329\end{array}$ & $\begin{array}{r}-0.03 \\
331\end{array}$ & $\begin{array}{r}-0.08 \\
332\end{array}$ & $\begin{array}{r}-0.20 \\
333\end{array}$ & $\begin{array}{r}-0.11 \\
334\end{array}$ & $\begin{array}{r}-0.12 \\
334\end{array}$ & $\begin{array}{r}-0.27 \\
334\end{array}$ & $\begin{array}{r}-0.28 \\
334\end{array}$ & $\begin{array}{r}-0.21 \\
330\end{array}$ & $\begin{array}{r}-0.20 \\
302\end{array}$ & $\begin{array}{r}-0.22 \\
298\end{array}$ \\
\hline & 10.0 & $\begin{array}{r}-0.03 \\
329\end{array}$ & $\begin{array}{r}-0.05 \\
331\end{array}$ & $\begin{array}{r}-0.06 \\
332\end{array}$ & $\begin{array}{r}-0.13 \\
333\end{array}$ & $\begin{array}{r}-0.06 \\
334\end{array}$ & $\begin{array}{r}-0.07 \\
334\end{array}$ & $\begin{array}{r}-0.22 \\
334\end{array}$ & $\begin{array}{r}-0.23 \\
334\end{array}$ & $\begin{array}{r}-0.18 \\
330\end{array}$ & $\begin{array}{r}-0.14 \\
302\end{array}$ & $\begin{array}{r}-0.16 \\
298\end{array}$ \\
\hline & 11.2 & $\begin{array}{r}0.02 \\
329\end{array}$ & $\begin{array}{r}0.03 \\
331\end{array}$ & $\begin{array}{r}-0.04 \\
332\end{array}$ & $\begin{array}{r}-0.11 \\
333\end{array}$ & $\begin{array}{r}-0.07 \\
334\end{array}$ & $\begin{array}{r}-0.12 \\
334\end{array}$ & $\begin{array}{r}-0.25 \\
334\end{array}$ & $\begin{array}{r}-0.22 \\
334\end{array}$ & $\begin{array}{r}-0.15 \\
330\end{array}$ & $\begin{array}{r}-0.09 \\
302\end{array}$ & $\begin{array}{r}-0.23 \\
298\end{array}$ \\
\hline & 12.5 & $\begin{array}{r}0.00 \\
329\end{array}$ & $\begin{array}{r}0.00 \\
331\end{array}$ & $\begin{array}{r}-0.04 \\
332\end{array}$ & $\begin{array}{r}-0.14 \\
333\end{array}$ & $\begin{array}{r}-0.12 \\
334\end{array}$ & $\begin{array}{r}-0.15 \\
334\end{array}$ & $\begin{array}{r}-0.31 \\
334\end{array}$ & $\begin{array}{r}-0.31 \\
334\end{array}$ & $\begin{array}{r}-0.27 \\
330\end{array}$ & $\begin{array}{r}-0.09 \\
302\end{array}$ & $\begin{array}{r}-0.25 \\
298\end{array}$ \\
\hline & 14.0 & $\begin{array}{r}0.05 \\
329\end{array}$ & $\begin{array}{r}0.01 \\
331\end{array}$ & $\begin{array}{r}-0.02 \\
332\end{array}$ & $\begin{array}{r}-0.13 \\
333\end{array}$ & $\begin{array}{r}-0.11 \\
334\end{array}$ & $\begin{array}{r}-0.15 \\
334\end{array}$ & $\begin{array}{r}-0.30 \\
334\end{array}$ & $\begin{array}{r}-0.28 \\
334\end{array}$ & $\begin{array}{r}-0.24 \\
330\end{array}$ & $\begin{array}{r}-0.10 \\
302\end{array}$ & $\begin{array}{r}-0.24 \\
298\end{array}$ \\
\hline & 16.0 & $\begin{array}{r}0.06 \\
329\end{array}$ & $\begin{array}{r}0.01 \\
331\end{array}$ & $\begin{array}{r}-0.01 \\
332\end{array}$ & $\begin{array}{r}-0.13 \\
333\end{array}$ & $\begin{array}{r}-0.12 \\
334\end{array}$ & $\begin{array}{r}-0.10 \\
334\end{array}$ & $\begin{array}{r}-0.21 \\
334\end{array}$ & $\begin{array}{r}-0.21 \\
334\end{array}$ & $\begin{array}{r}-0.25 \\
330\end{array}$ & $\begin{array}{r}-0.10 \\
302\end{array}$ & $\begin{array}{r}-0.18 \\
298\end{array}$ \\
\hline
\end{tabular}

Pearson correlation coefficients and number of observations. Black boxes show correlations between DPOAE level and pure tone threshold at the corresponding frequency. 
Table 3. RMSPEs by model and pure tone threshold frequency.

\begin{tabular}{rrrr}
\hline & $\begin{array}{r}\text { Full } \\
\text { Model }\end{array}$ & $\begin{array}{c}\text { Mean } \\
\text { Audio } \\
\text { Model }\end{array}$ & $\begin{array}{c}\text { Difference } \\
\text { Mean Audio } \\
\text { - Full) }\end{array}$ \\
\hline $\begin{array}{r}\text { Freq } \\
(\mathrm{kHz})\end{array}$ & $\begin{array}{r}\text { RMSPE } \\
(\mathrm{dB})\end{array}$ & $\begin{array}{r}\text { RMSPE } \\
(\mathrm{d} B)\end{array}$ \\
\hline 0.25 & 5.0 & 5.4 & 0.4 \\
0.5 & 5.0 & 6.0 & 1.0 \\
1 & 5.3 & 5.8 & 0.5 \\
2 & 5.5 & 7.6 & 2.1 \\
3 & 5.5 & 6.4 & 0.9 \\
4 & 5.5 & 6.8 & 1.3 \\
6 & 6.0 & 7.4 & 1.4 \\
8 & 6.5 & 8.3 & 1.8 \\
9 & 9.2 & 9.8 & 0.6 \\
10 & 10.2 & 12.0 & 1.8 \\
11.2 & 10.7 & 11.5 & 0.8 \\
12.5 & 11.9 & 13.0 & 1.1 \\
14 & 16.5 & 17.5 & 1.0 \\
16 & 18.9 & 20.1 & 1.2 \\
\hline
\end{tabular}

Freq $=$ Frequency, RMSPE $=$ Root mean squared prediction error 
Table 4. Mean group residuals by pure tone threshold frequency

\begin{tabular}{|c|c|c|c|c|c|c|c|c|c|c|c|c|c|c|}
\hline & \multicolumn{14}{|c|}{ Pure Tone Threshold Frequency (kHz) } \\
\hline & 0.25 & 0.5 & 1 & 2 & 3 & 4 & 6 & 8 & 9 & 10 & 11.2 & 12.5 & 14 & 16 \\
\hline \multicolumn{15}{|c|}{$\begin{array}{l}\text { Noise Exposure } \\
\text { Group }\end{array}$} \\
\hline $\begin{array}{l}\text { Non-Veteran } \\
\text { Firearms }\end{array}$ & 1.7 & -0.5 & -0.9 & -0.1 & -0.7 & -0.2 & 0.7 & -2.9 & 0.8 & 1.4 & 1.0 & -2.0 & -5.5 & -7.3 \\
\hline $\begin{array}{l}\text { Non-Veteran } \\
\text { Controls }\end{array}$ & -0.7 & 0.0 & -0.1 & -1.0 & -1.0 & -0.9 & -0.8 & -0.8 & -0.4 & -1.2 & -1.6 & -1.7 & -0.1 & 0.1 \\
\hline Veterans & 0.2 & 0.1 & 0.2 & 0.8 & 0.6 & 0.6 & 2.1 & 0.8 & 1.0 & -0.1 & -0.7 & 0.7 & 3.6 & 3.9 \\
\hline \multicolumn{15}{|l|}{ Age Group } \\
\hline $19-25$ years & 0.5 & 0.6 & -0.1 & -0.9 & -0.6 & -1.1 & -1.0 & -1.8 & -0.3 & -1.8 & -2.3 & -2.3 & -3.7 & -4.3 \\
\hline $26-30$ years & 0.4 & -0.2 & -0.1 & 0.9 & 0.4 & 0.5 & 1.9 & 0.7 & 0.8 & -0.7 & -1.2 & -0.9 & 2.4 & 0.5 \\
\hline $31-35$ years & -0.9 & -0.2 & 0.3 & 0.2 & 0.0 & 0.4 & 1.6 & 0.7 & 0.8 & 1.1 & 0.7 & 2.1 & 5.4 & 8.6 \\
\hline \multicolumn{15}{|c|}{ Tinnitus Group } \\
\hline No & -0.4 & -0.5 & -0.5 & -0.5 & -0.4 & -0.5 & 0.5 & -0.3 & 0.2 & -0.2 & -1.1 & -1.0 & 0.3 & 0.2 \\
\hline Yes & 1.1 & 1.3 & 1.4 & 1.8 & 1.0 & 1.5 & 2.3 & 0.7 & 1.2 & -0.9 & -0.4 & 1.4 & 5.4 & 6.3 \\
\hline
\end{tabular}

Residuals are shown in dB. 


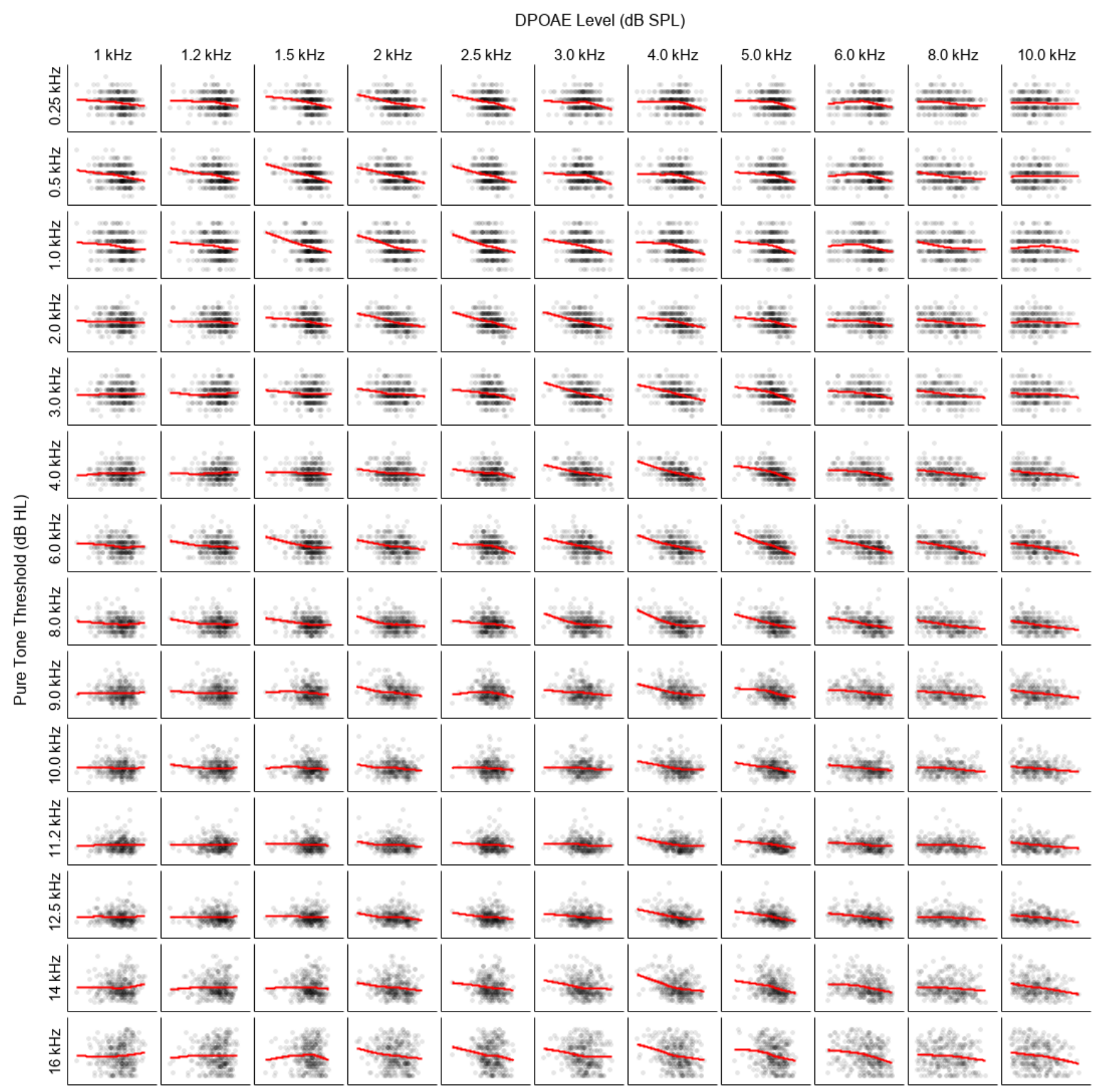

Supplemental Data Figure 1. Relationship between pure tone thresholds and DPOAE levels across frequency. The strongest correlations between audiometric thresholds and DPOAE levels are not necessarily observed at corresponding frequencies. Black dots show observed DPOAE level and pure tone threshold data for individual ears. Pure tone thresholds are plotted with larger (poorer) thresholds at the top of each plot and smaller thresholds at the bottom. Lower DPOAE levels are shown on the left side of the plot and higher levels are on the right side. Red lines show LOESS smooth functions. 